\title{
Invasion by Matrix Metalloproteinase-Expressing Cells Is Important for Primitive Streak Formation in Early Chick Blastoderm
}

\author{
Kazue Mogi ${ }^{a}$ Ryuji Toyoizumi ${ }^{a-c}$ \\ a Research Institute for Integrated Sciences, ${ }^{b}$ Department of Biological Sciences, Faculty of Science, and \\ 'High-Tech Research Center, Kanagawa University, Hiratsuka, Japan
}

\begin{abstract}
Key Words
Matrix metalloproteinase-2 - Membrane-type 3 matrix metalloproteinase - Stromelysin-3 - Basement membrane • Ingression
\end{abstract}

\begin{abstract}
Epiblast cells in the early chick embryo differentiate to form all three germ layers through ingression of cells at the primitive streak across the basement membrane that underlies the epiblast. We tested the idea that degradation of the extracellular matrix components by matrix metalloproteinase(s) (MMPs) is involved in this process. Epiblast cells and primitive streak cells were dissociated into single cells and seeded onto a reconstituted basement membrane gel in vitro. Following overnight culture, approximately half the cells made holes in the substratum by dissolving the gel matrix. This invasive phenomenon was reproduced in vitro even when the cells were cultured upside down using a hanging culture system. We detected gelatinase activity in the culture supernatants from both prestreak epiblast cells and primitive streak cells. Pro-MMP-2 was detected in the culture media of the prestreak/streak cells as a 72-kDa band by gelatin zymography. In RT-PCR experiments, mRNAs for MMP-2, membrane-type (MT)3-MMP and MMP-11 (stromelysin-3) were expressed in the epiblast cells before and during primitive streak formation. Injection of GM 6001 or other MMP inhibitors into the subgerminal cavity of the embryo inhibited the formation of the primitive streak and/or the primitive groove
\end{abstract}

in more than $82 \%$ of the injected embryos. On the other hand, injection of a negative control compound instead of GM 6001 did not cause substantial inhibition. These results suggest that MMPs are involved in the enzymatic degradation of the basement membrane underlying the epiblast and are thus important for the ingression of mesendodermal cells along the primitive streak.

Copyright $\odot 2010$ S. Karger AG, Basel

\section{Introduction}

Matrix metalloproteinases (MMPs) form a large family that includes at least 24 types of MMPs in humans and other vertebrates [Harrison et al., 2004; Werner et al., 2007]. MMPs play essential roles in disorganizing

\section{Abbreviations used in this paper}

E-G\&K Eyal-Giladi and Kochav

EHS Engelbreth-Holm-Swarm

$\mathrm{H} \& \mathrm{H} \quad$ Hamburger and Hamilton

MMP matrix metalloproteinase

MT membrane-type

PC protein convertase

PIU protease inhibitor units

SMPI Streptomyces metalloprotease inhibitor

TIMP tissue inhibitor of matrix metalloproteinase

\section{KARGER}

Fax +4161306 1234

E-Mail karger@karger.ch

www.karger.com
(C) 2010 S. Karger AG, Basel

$1422-6405 / 10 / 1921-0001 \$ 26.00 / 0$

Accessible online at:

www.karger.com/cto
Dr. Kazue Mogi

Research Institute for Integrated Sciences, Kanagawa University

Tsuchiya 2946, Hiratsuka city 259-1293 (Japan)

Tel. +81 46359 4111, ext. 2733, Fax +81 463589684

E-Mail toyoik02@kanagawa-u.ac.jp 
the basement membrane during both cancer cell invasion [Bischof et al., 2000; Pilka et al., 2003; Hofmann et al., 2005; Vihinen et al., 2005] and the implantation of mammalian embryos [Bischof et al., 2000; Pilka et al., 2003].

In Xenopus laevis embryos, the following MMP members have been identified: XMMP-2 (gelatinase A) [Jung et al., 2002; Hasebe et al., 2006], XMMP-7 [Harrison et al., 2004], XMMP-9 (gelatinase B) [Carinato et al., 2000], XMMP-11 (stromelysin-3) [Patterton et al., 1995; Ishizuya-Oka et al., 1996, 2000], XMMP-18 (Xenopus collagenase-4) [Stolow et al., 1996; Tomlinson et al., 2008] and XMMP-21 [Yang et al., 1997; Yang and Kurkinen, 1998; Ahokas et al., 2002]. In addition, membrane-associated MMPs that activate other MMPs by proteolytic cleavage have been identified. These include XMMP-14 [Xenopus membrane-type (MT)1-MMP] [Harrison et al., 2004; Hasebe et al., 2006], XMMP-15 (XMT2-MMP) [Harrison et al., 2004] and XMMP-16 (XMT3-MMP) [Jung et al., 2002]. Cynops matrix metalloproteinase, which shows homology to XMMP-21, has been identified in Cynops embryos [Suzuki et al., 2001]. Because the expression of both XMMP-21 [Ahokas et al., 2002] and Cynops matrix metalloproteinase [Suzuki et al., 2001] is detected at the gastrula stage, it is possible that homologues of MMP-21 might play a role in amphibian gastrulation.

In chicks (Gallus gallus domesticus), MMP-2 (gelatinase A, type IV collagenase) was first isolated as a proenzyme from fibroblasts [Chen et al., 1991]. The mRNA for the 72-kDa $M M P-2$ in fibroblasts was later detected using RT-PCR [Aimes et al., 1994]. Thereafter, mRNAs for the 72-kDa MMP-2 and 2 kinds of MT-MMPs (MT1-MMP and $M T 3-M M P$ ) were reported to be expressed in 2- or 3 -day-old chick embryos [Yang et al., 1996]. Chick MMP2 is also expressed during the development of the heart [Alexander et al., 1997; Cai et al., 2000; Cai and Brauer, 2002; Linask et al., 2005] and neural crest [Cai et al., 2000; Cai and Brauer, 2002]. Therefore, the MMP-2 enzyme is considered to be an important player in the morphogenesis of the early chick embryo.

In the chick embryo, some of the epiblast cells that carry the HNK-1 carbohydrate epitope on their surfaces ingress at the primitive streak and then form the ectoderm, mesoderm and endoderm [Stern and Canning, 1990; Mogi et al., 2000]. Ingressing epiblast cells must dissolve the basement membrane underlying the epiblast sheet because the continuity of the basement membrane in the area pellucida, achieved at the prestreak stage, is disorganized only at the region of the primitive streak during gastrulation movement [Duband and Thiery,
1982; Zagris et al., 2000; Soulintzi and Zagris, 2007]. The cytological and molecular mechanisms responsible for this proteolytic process are as yet unknown, but in 1984, Bellairs and van Peteghem [1984] proposed that ingression of the mesendoderm is analogous to cell invasion by malignant cells.

In this report, we test the idea that cooperation between cell adhesion to the substratum and proteolysis by MMPs is necessary for the ingression of epiblast cells during avian gastrulation. We seeded dissociated epiblast cells at Eyal-Giladi and Kochav (E-G\&K) [Eyal-Giladi and Kochav, 1976] stage X-XIII or primitive streak cells at Hamburger and Hamilton $(\mathrm{H} \& \mathrm{H})$ [Hamburger and Hamilton, 1951] stage 3 onto a thick basement membrane gel. Half of the dissociated cells made holes on the substratum by dissolving the gel matrix to which they adhered, as we previously reported [Toyoizumi and Takeuchi, 1995; Toyoizumi et al., 1997]. We also observed a similar invasive motion in an upside-down hanging culture system, in which gravity, acting on the cultured cells, pulled the cells from the substratum, suggesting that directionality of cell invasion was not controlled by gravity.

We then attempted to measure the proteolytic activity. The epiblast cells/primitive streak cells had collagenase activity, and the activity was suppressed by Streptomyces metalloprotease inhibitor (SMPI). After the culture of epiblast cells, the conditioned media were analyzed for MMP activity using gelatin zymography. A single band was detected at the same position as the $72-\mathrm{kDa}$ marker, pro-MMP-2. RT-PCR analysis revealed that $M M P-2$, MT3-MMP and stromelysin-3 (MMP-11) are expressed in the epiblast cells and primitive streak cells at the prestreak and primitive streak stages, respectively. When GM 6001 or a mixture of other MMP inhibitors was injected into the subgerminal cavity of the embryos of freshly laid eggs, these inhibitors suppressed formation of the primitive streak and/or the primitive groove in more than $82 \%$ of the injected embryos.

Taken together, these results suggest that epiblast cells secrete several MMPs prior to and during ingression, and that penetration of the presumptive mesendoderm through the primitive streak is assured by the continuous attachment of the epiblast cells to the substratum and proteolysis of the basement membrane by MMPs, similar to the process of cancer cell invasion. 


\section{Materials and Methods}

Observation of the Behavior of Epiblast Cells and Primitive Streak Cells in Hanging Cultures

Fertilized chicken eggs were incubated at $37^{\circ} \mathrm{C}$ for $12-18 \mathrm{~h}$. At the appropriate developmental stage, the blastoderm was dissected out together with the vitelline membrane and transferred to a sterile dish filled with $\mathrm{Ca}^{2+}$ - and $\mathrm{Mg}^{2+}$-free PBS. The developmental stage was identified according to the standard E-G\&K [Eyal-Giladi and Kochav, 1976] and $\mathrm{H} \& \mathrm{H}$ [Hamburger and Hamilton, 1951] developmental tables. Epiblast cells or primitive streak cells were excised from the blastoderm using a pair of glass needles and were then dissociated into single cells by gentle pipetting in $\mathrm{Ca}^{2+}$ and $\mathrm{Mg}^{2+}$-free Spinner's MEM as described previously [Toyoizumi et al., 1997]. The single cells were then seeded into culture dishes filled with RPMI 1640 medium (Gibco) containing 2\% chicken serum (Cosmo Bio Co., Japan) or $0.2 \%$ Mito+ serum extender (Becton Dickinson Co.). Before seeding, the bottoms of the culture dishes were coated with a high concentration $(1 \mathrm{mg} / \mathrm{ml})$ of laminin solution (Biomedical Technologies, USA) or with EngelbrethHolm-Swarm (EHS) solution (obtained from the EHS murine sarcoma; $6.6 \mathrm{mg} / \mathrm{ml}$; Iwaki Glass Co., Japan), which contains laminin [Kleinman et al., 1982] and type IV collagen [Kleinman et al., 1982; Yurchenco and Ruben, 1987] as the major components.

The single cells were incubated in $5 \% \mathrm{CO}_{2}$ at $37^{\circ} \mathrm{C}$ for $2-3 \mathrm{~h}$. They were then examined to determine whether or not they had attached to the gel. After the medium was replaced with fresh medium, some of the dishes of attached cells were cultured under normal gravitational conditions for 16-24 h. The remaining dishes of attached cells were cultured upside down, with the gel support occupying the roof of the inverted dish, which was floating in a 'pond' of medium (fig. 1). In this report, we refer to this technique as hanging culture. After culture, the single cells and gel surface were observed with a phase-contrast microscope and photographed. Some of the samples were fixed with $0.5-2 \%$ glutaraldehyde, washed in $\mathrm{Ca}^{2+}$ - and $\mathrm{Mg}^{2+}$-free PBS, dehydrated according to normal procedures and observed with a scanning electron microscope (T-20, Jeol).

Measurement of MMP Activity in Epiblast Cells and

Primitive Streak Cells, and Alteration of MMP Activity

by MMP Inhibitor

E-G\&K stage X-XIII epiblast cells and $\mathrm{H} \& \mathrm{H}$ stage 3 primitive streak cells were excised from the blastoderm and fragmented into smaller pieces using glass needles. They were transferred to uncoated 96-well polystyrene plates filled with RPMI 1640 medium containing $0.2 \% \mathrm{Mito}+$ serum extender for serum-free culture and were incubated in $5 \% \mathrm{CO}_{2}$ at $37^{\circ} \mathrm{C}$ for $48 \mathrm{~h}$. After culture, conditioned media were collected, and cell debris was removed by centrifugation. The supernatants were incubated with an MMP activity measurement kit (YU-18001, Yagai Co., Japan) at $42^{\circ} \mathrm{C}$ for $4 \mathrm{~h}$ in order to detect MMP-2/MMP-9 (gelatinase A/B) activity. The fluorescence intensity of the degraded substrate (FITC-labeled type IV collagen) was measured with a fluorescence spectrophotometer (Hitachi F-2000; excitation wavelength $495 \mathrm{~nm}$, emission wavelength $520 \mathrm{~nm}$ ), and MMP activity in the conditioned media was quantified by comparing the fluorescence intensity to that of the standard enzyme.

Stage XIII epiblasts were cultured for $48 \mathrm{~h}$, and conditioned medium from the cells was divided into 2 equal volumes. One

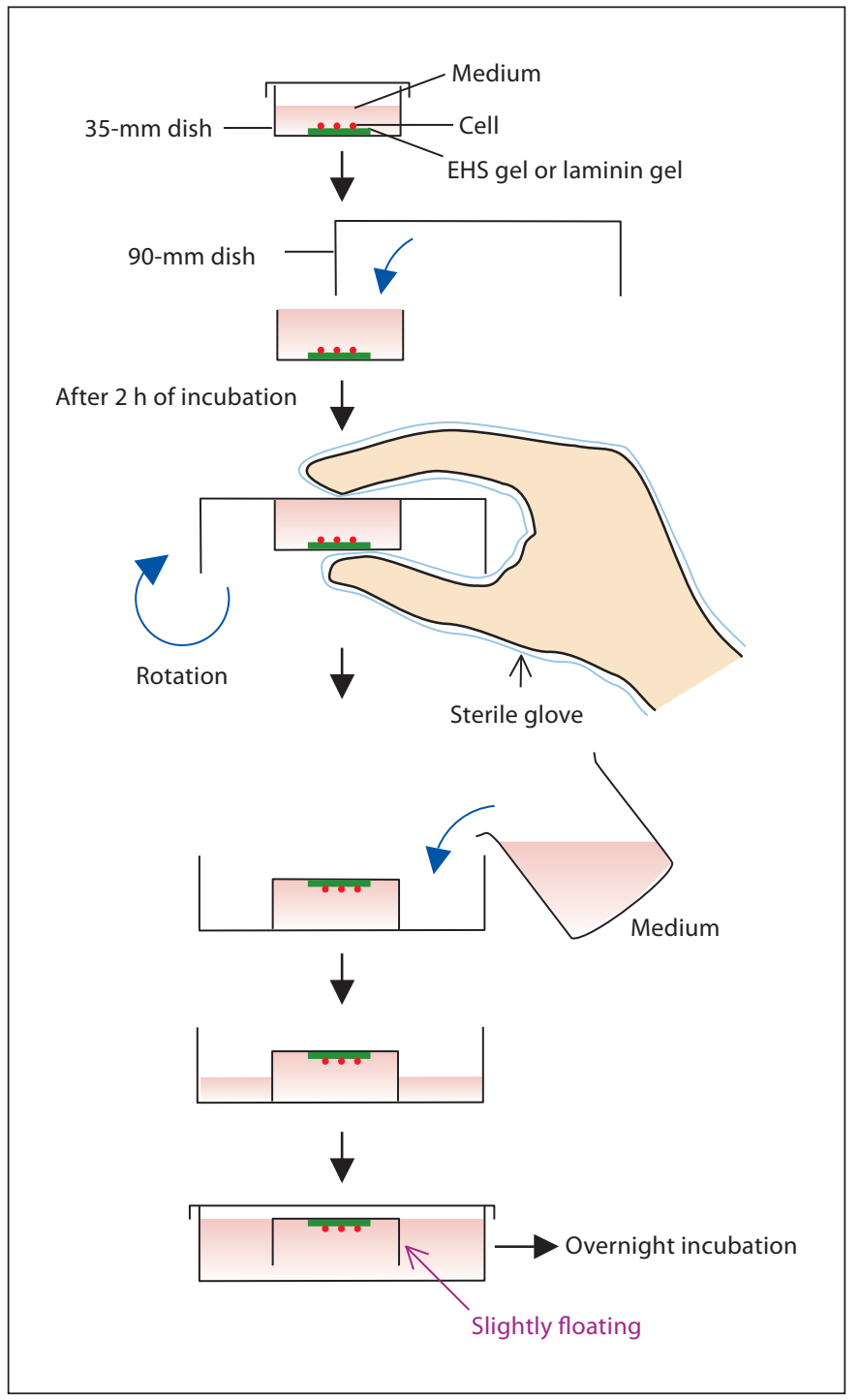

Fig. 1. The hanging culture technique used to test the effect of gravity on invasion by single cells. When the embryos reached the desired stage, epiblast cells or primitive streak cells were excised using a pair of glass needles, dissociated into single cells and seeded onto culture dishes filled with RPMI 1640 medium containing $2 \%$ chicken serum. Prior to seeding, the bottoms of the culture dishes had been coated with laminin gel or EHS gel. After 2-3 h of culture, single cells were examined to determine whether or not they had attached to the gel substratum. The first medium was then exchanged with fresh medium, and immediately afterwards, the cover on the $35-\mathrm{mm}$ culture dish was removed, and a $90-\mathrm{mm}$ culture dish was placed over the $35-\mathrm{mm}$ dish. Sterile gloves were worn while handling the dishes. The two dishes were held together and then inverted. RPMI 1640 medium containing 2\% chicken serum was then poured into the $90-\mathrm{mm}$ culture dish, causing the smaller dish to float slightly. Finally, a $90-\mathrm{mm}$ culture dish cover was placed over the top, and the single cells were incubated at $37^{\circ} \mathrm{C}$ in $5 \% \mathrm{CO}_{2}$ for $16-24 \mathrm{~h}$ in this orientation. As a control experiment, some of the single cells were cultured in the normal orientation. 

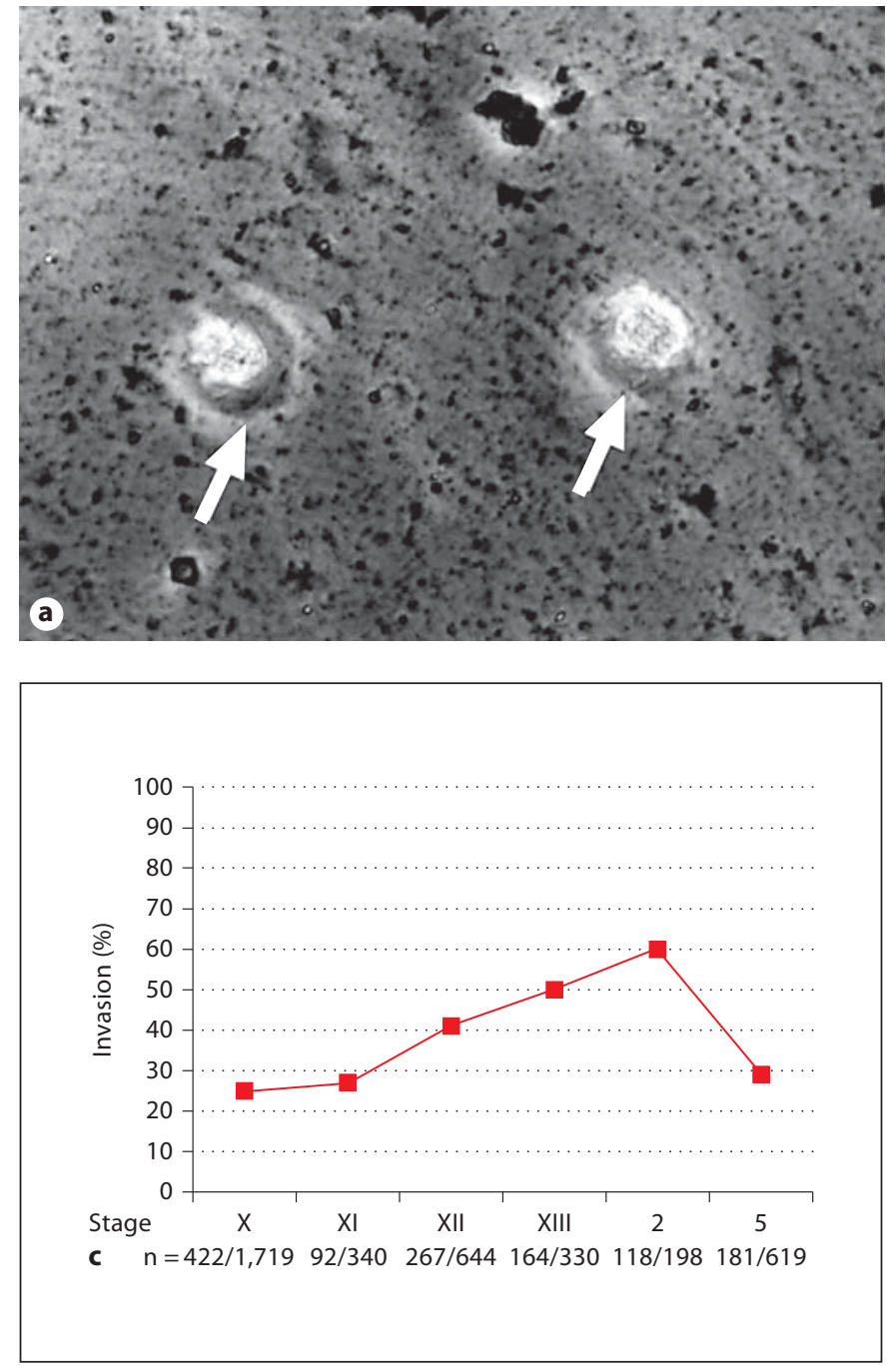

Fig. 2. a, b Epiblast cells and primitive streak cells make holes by dissolving the gel substratum following overnight culture. Epiblast cells of E-G\&K stage XIII embryos cultured on laminin gel (normal orientation; a) and primitive streak cells of $\mathrm{H} \& \mathrm{H}$ stage 3 embryos cultured on laminin gel (hanging orientation; b) are shown. In both culture conditions, circular holes in the gel and cells invading the holes (white arrows) can be seen. c Stage dependency of the proportion of invasive cells cultured on EHS gel (for $24 \mathrm{~h}$ ) during blastodermal stages. The proportion of invasive cells

volume was measured directly, and to the other we added the MMP inhibitor SMPI at final concentrations of 7,670 or 11,500 protease inhibitor units (PIU)/mI, just before the measurement of MMP activity.

The results of these measurements are shown in figures 2 and 3 as mean values with the standard deviations indicated with error bars. Statistical analysis was performed for the collagenase activities using a paired test at a $2.5 \%$ significance level.
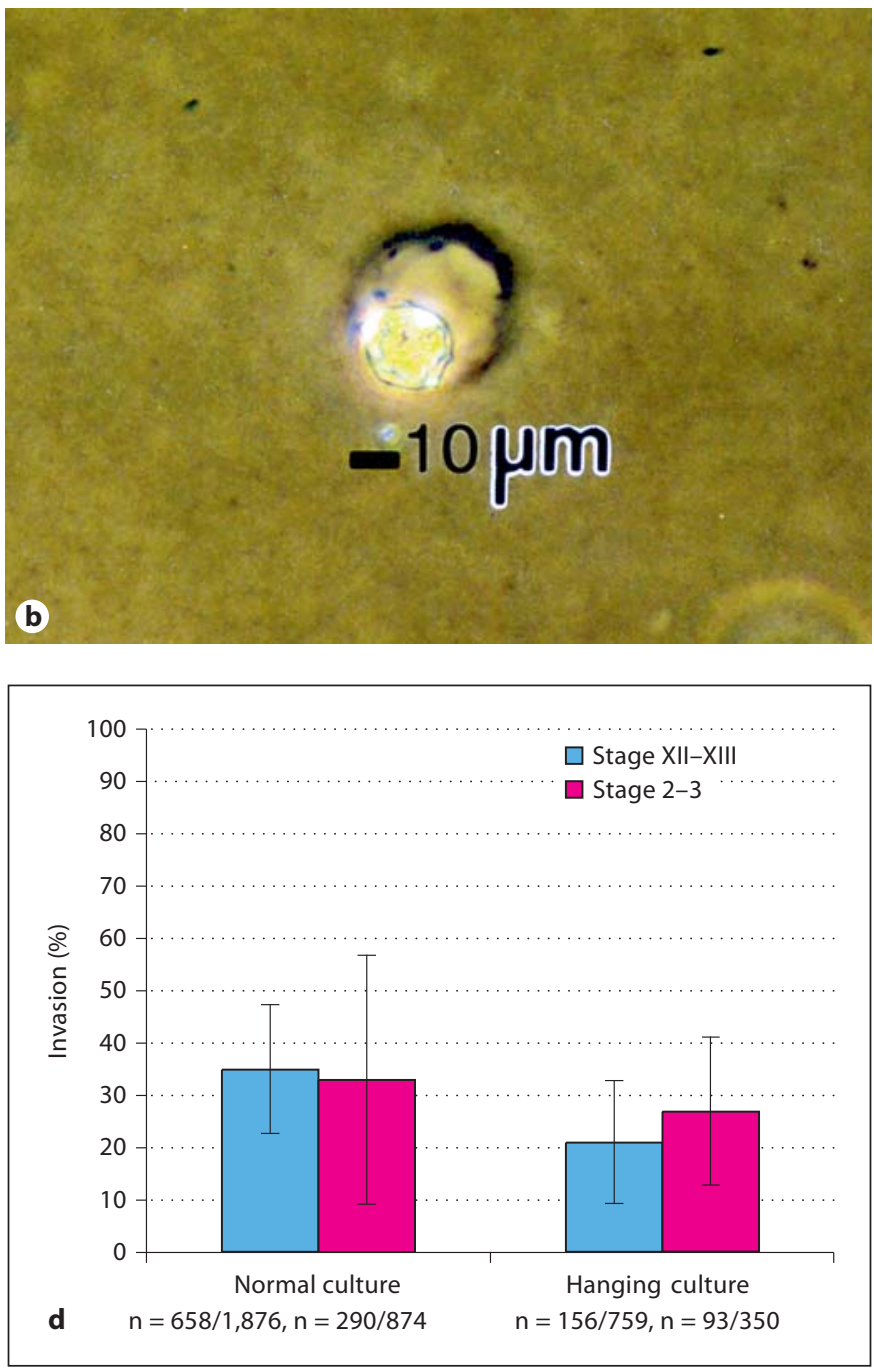

peaked at $60 \%$ in $\mathrm{H} \& \mathrm{H}$ stage 2 epiblast cells around the primitive streak. d The proportion of cells invading the laminin gel or EHS gel in normal culture or hanging culture $(24 \mathrm{~h})$. A substantial proportion of the cells invaded the gel in either orientation, and there were no significant differences in the proportion of invasive cells between the two orientations in either stage XII-XIII cells or stage $2-3$ cells ( $p>0.1$ with $t$ test). All of the cells were cultured with RPMI 1640 medium containing 2\% chicken serum.

Measurement of the Molecular Weight of MMP Using Gelatin Zymography

Using gelatin zymography, we investigated whether media conditioned by the epiblast cells or primitive streak cells contained MMP enzymes. Epiblast cells at E-G\&K stage XIII or primitive streak cells at $\mathrm{H} \& \mathrm{H}$ stage 3 were seeded into the wells of a 96-well plate coated with fibronectin, and the cells were cultured at $37^{\circ} \mathrm{C}$ for $12 \mathrm{~h}$ in serum-free conditions (RPMI 1640 medium containing $0.2 \%$ Mito + serum extender). After the culture, the conditioned medium was collected from the wells, and after a 
brief centrifugation, the supernatants were electrophoresed in a gel containing gelatin and processed using a gelatin zymography kit (Yagai). The manufacturer informed us that pro-MMPs have been found to be activated without enzymatic processing by electrophoresis in an SDS-polyacrylamide gel containing gelatin in the presence of enzymatic reaction buffer. After electrophoresis, the SDS was washed out using Triton X-100 solution. In this way, we could potentially detect pro-MMP-2, active-form MMP-2, pro-MMP-9, active-form MMP-9, active stromelysin and MTMMPs with the zymography kit.

Investigation of the Expression Profiles of the MMP $m R N A s$ in the Early Chick Embryo by RT-PCR Using Normal or Degenerate Primers

MMP-2 and MT3-MMP mRNAs are expressed in chick embryos at H\&H stage 12-14 [Yang et al., 1996]. Here, we used RTPCR to investigate whether these MMPs were expressed in epiblast cells before or during primitive streak formation. The following primer pairs were designed by Yang et al. [1996]: MMP-2 forward primer, 5'-ACC CCG ATG TGG CCA ATT ACA ACT T3', and MMP-2 reverse primer, 5'-TAA AGG GAA ACT TGC AGG GCT GTC-3'; MT3-MMP forward primer, 5'-AGA ATC ACC CCA GGG AGC CTT TGT-3', and MT3-MMP reverse primer, 5'-GAT CTC ACC CAC TCT TGC ATA GAG CGT-3'. To detect novel MMP mRNAs from the early blastoderm, a degenerate primer pair designed by Yang et al. [1996] was used: Y35 MMP forward primer, 5'-CCI MGI TGY GGI RWI CCI GA-3', and Y36 MMP reverse primer, 5'-TGI CCI ADY TCR TGI RCI GCI AC-3'. The following primer pair was used as a positive control: GAPDH forward primer, 5'-ACC ATC AAG TCC ACA ACA CG-3', and GAPDH reverse primer, 5' ${ }^{\prime}$-AAG GTC ATC CCA GAG CTG AA-3'.

The E-G\&K stage XIII area pellucida epiblast sheet, H\&H stage 3-3+ primitive streak cells and $\mathrm{H} \& \mathrm{H}$ stage $3-3+$ epiblast sheet around the primitive streak were excised from the blastoderm, and total RNA was extracted from each using Isogen (Nippon Gene Co., Japan). Ready-To-Go RT-PCR Beads with an oligo(dT) primer (Amersham Biosciences Co.) and $1 \mu \mathrm{g}$ of total RNA were mixed in the buffer, and an iCycler (Bio-Rad) was used to heat the test tube to $42^{\circ} \mathrm{C}$ for $30 \mathrm{~min}$ for reverse transcription and then to $95^{\circ} \mathrm{C}$ for $5 \mathrm{~min}$ to stop the reaction. After the reverse transcription step, each primer pair was added to the reaction buffer. The PCR program consisted of 1 cycle of preincubation at $95^{\circ} \mathrm{C}$ for $2 \mathrm{~min}$ and 35 cycles of denaturing at $95^{\circ} \mathrm{C}$ for $1 \mathrm{~min}$, annealing at $65^{\circ} \mathrm{C}$ for $1 \mathrm{~min}$ and extension at $72^{\circ} \mathrm{C}$ for $1 \mathrm{~min}$, followed by a final extension step at $72^{\circ} \mathrm{C}$ for $7 \mathrm{~min}$. For RT-PCR using the degenerate primers, we determined in our preliminary experiments that the proper annealing temperature is in the range between 45 and $60^{\circ} \mathrm{C}$. PCR products were ligated into a plasmid vector (pGEM-T-Easy Vector System, Promega Co.), and the plasmid sequence was confirmed by normal cycle sequencing using a combination of a BigDye Terminator kit and the ABI Prism 310 Genetic Analyzer. The nucleotide sequence of each clone was translated in all reading frames for comparison against a protein sequence database using the BLASTx Program.

Injection of MMP Inhibitors into the Chick Subgerminal Cavity

MMP-2 inhibitor I (cis-9-octadecenoyl-N-hydroxylamide, oleoyl-N-hydroxylamide; Calbiochem Co., 444244), which tar- gets MMP-2, was dissolved in DMSO at $5 \mathrm{mg} / \mathrm{ml}$, and MMP inhibitor IV ( $\mathrm{HONH}-\mathrm{COCH}_{2} \mathrm{CH}_{2} \mathrm{CO}-\mathrm{Phe}-\mathrm{Ala}-\mathrm{NH}_{2}$; Calbiochem, 444271), which targets various MMPs, was dissolved in DMSO at $5 \mathrm{mg} / \mathrm{ml}$. The two inhibitors were mixed, and the mixture was then dissolved in an equal volume of sterilized water, so that the final concentrations of both inhibitors were $2.5 \mathrm{mg} / \mathrm{ml}$ in $50 \%$ DMSO. Similarly, the MMP inhibitor GM 6001 (Calbiochem) or the negative control compound for GM 6001 (N-t-butoxycarbonyl-L-leucyl-L-tryptophan methylamide; Calbiochem) was dissolved in DMSO solution at $10 \mathrm{mg} / \mathrm{ml}$ and added to an equal volume of sterilized water for a final concentration of $5 \mathrm{mg} / \mathrm{ml}$ in $50 \%$ DMSO. Before the inhibitors were microinjected into the embryo, Nile blue was added to the inhibitor solution at $0.5 \%(\mathrm{w} / \mathrm{v})$ as a tracer.

After removing the eggshell and most of the albumen, the whole blastoderm and total yolk, enveloped in an intact vitelline membrane, were transferred into a sterilized evaporating dish filled with Tyrode's solution for the injection. The mixture of MMP inhibitors, GM 6001 or the negative control compound for GM 6001 was injected into the subgerminal cavity (the space underlying the undifferentiated epiblast) of the unincubated blastoderm (probably stage X-XI) at a dose of $3.45 \mu \mathrm{g}$. After the injection, the embryos were moved into a sterilized crystallizing dish, covered by an air seal in a clean bench and incubated aseptically at $38^{\circ} \mathrm{C}$ for $24-27 \mathrm{~h}$ on a shaker at $30 \mathrm{rpm}$. As a control, an equal volume of $50 \%$ DMSO was injected into the subgerminal cavities of the blastoderms, and the eggs were incubated similarly. After the incubation, the blastoderms were isolated from the yolk, checked for primitive streak formation and photographed from the dorsal side with a charge-coupled device camera (Keyence, VB-7000/7010).

\section{Results}

\section{Epiblast Cells Invade Basement Membrane Gel}

Irrespective of the Effects of Gravity

Epiblast cells from E-G\&K stage X-XIII embryos and primitive streak cells from $\mathrm{H} \& \mathrm{H}$ stage 3 embryos were dissociated into single cells and seeded onto culture dishes coated with laminin gel or EHS gel, and the dishes were filled with a medium containing $2 \%$ chick serum. After 16-24 h of culture, the epiblast cells/primitive streak cells were observed with a phase-contrast microscope. Approximately half of the cells had a dark, circular outline indicating the formation of a hole in the gel (fig. 2a). As the epiblast cells developed, the proportion of cells invading the EHS gel increased. The proportion of invasive epiblast cells peaked at $60 \%$ at $\mathrm{H} \& \mathrm{H}$ stage 2 (initial streak stage) and then decreased to $29 \%$ at $\mathrm{H} \& \mathrm{H}$ stage 5 , when the embryo forms the definitive ectoderm, mesoderm and endoderm (fig. 2c).

In order to evaluate the effect of gravity on the invasive motion of the single cells, the cells were cultured for 2-3 h to allow them to adhere, and then the culture dish- 


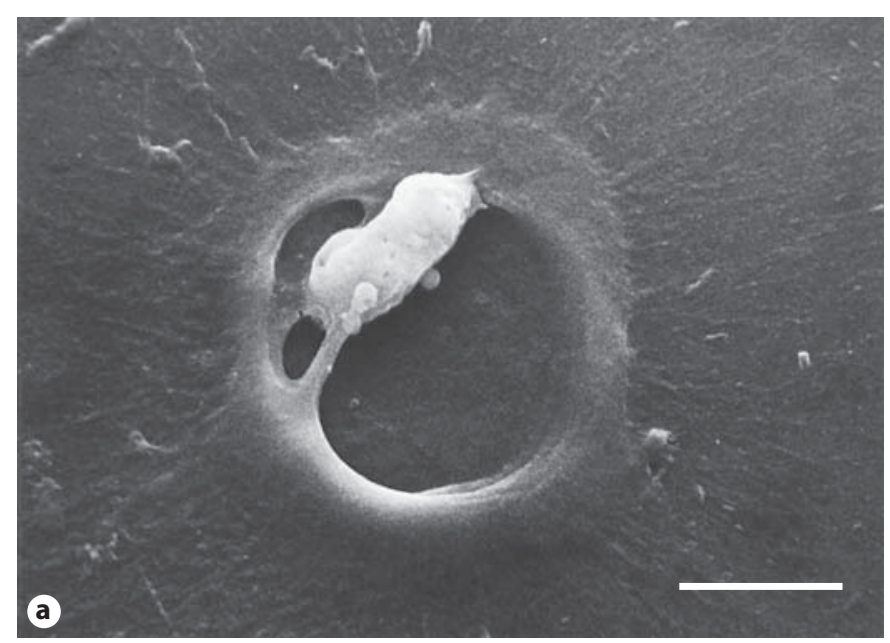

Fig. 3. Epiblast cells and primitive streak cells secrete proteinase(s) to dissolve basement membrane. All the experiments shown in this figure were carried out in RPMI 1640 medium containing $0.2 \%$ Mito+ serum extender (serum-free conditions). a Scanning electron microscope photograph of an E-G\&K stage XIII epiblast cell cultured in serum-free conditions on an EHS gel for $48 \mathrm{~h}$. Note that the cell has invaded the gel and adhered to the side of the hole. Note also that the gel surface shows traces of enzymatic proteolysis. Scale bar $=10 \mu \mathrm{m}$. b After $48 \mathrm{~h}$ of culture in 96-well plates, conditioned media from the epiblast cells of E-G\&K stage X-XIII embryos or primitive streak (PS) cells of H\&H stage $3 \mathrm{em}-$ bryos were checked for enzymatic activity of MMP-2/MMP-9 (also known as gelatinase $\mathrm{A} / \mathrm{B}$ or type IV collagenase $\mathrm{A} / \mathrm{B}$ ) by measuring the fluorescence level of the degraded substrates. The fluorescence intensity showed that the enzymatic activities ranged from 0.06 to 0.12 units $/ \mathrm{ml}$ per embryo. There was no significant difference in enzymatic activity between the developmental stages $(p>0.1$ with $t$ test). $c$ The conditioned media from stage XIII epiblasts were divided into 2 equal volumes; one was supplemented with an MMP inhibitor (SMPI, 7,670 or 11,500 PIU/mI) before the measurement of the gelatinase activity and the other was left untreated as a control. The MMP inhibitor significantly reduced enzymatic activity in the conditioned media ( $p<0.025$ with paired $t$ test), suggesting that the enzyme secreted in the supernatants was MMP. d Gelatin zymography of the serum-free culture supernatant. Several pieces of epiblast explants at the prestreak stage were seeded onto a fibronectin-coated 96 -well plate and cultured at $37^{\circ} \mathrm{C}$ for $12 \mathrm{~h}$. After culture, the conditioned medium was analyzed by gelatin zymography. A weak band was located at the $72-\mathrm{kDa}$ molecular weight position (arrow), at the same position as pro-MMP-2. The presence of this MMP band demonstrated that epiblast cells secrete MMP-2 before primitive streak formation. We did not detect the active form of MMP-2 in 4 replications of the zymography, possibly because only small pieces of the explants could be obtained from the early blastoderm. Left lane: molecular markers; right lane: the experimental sample.
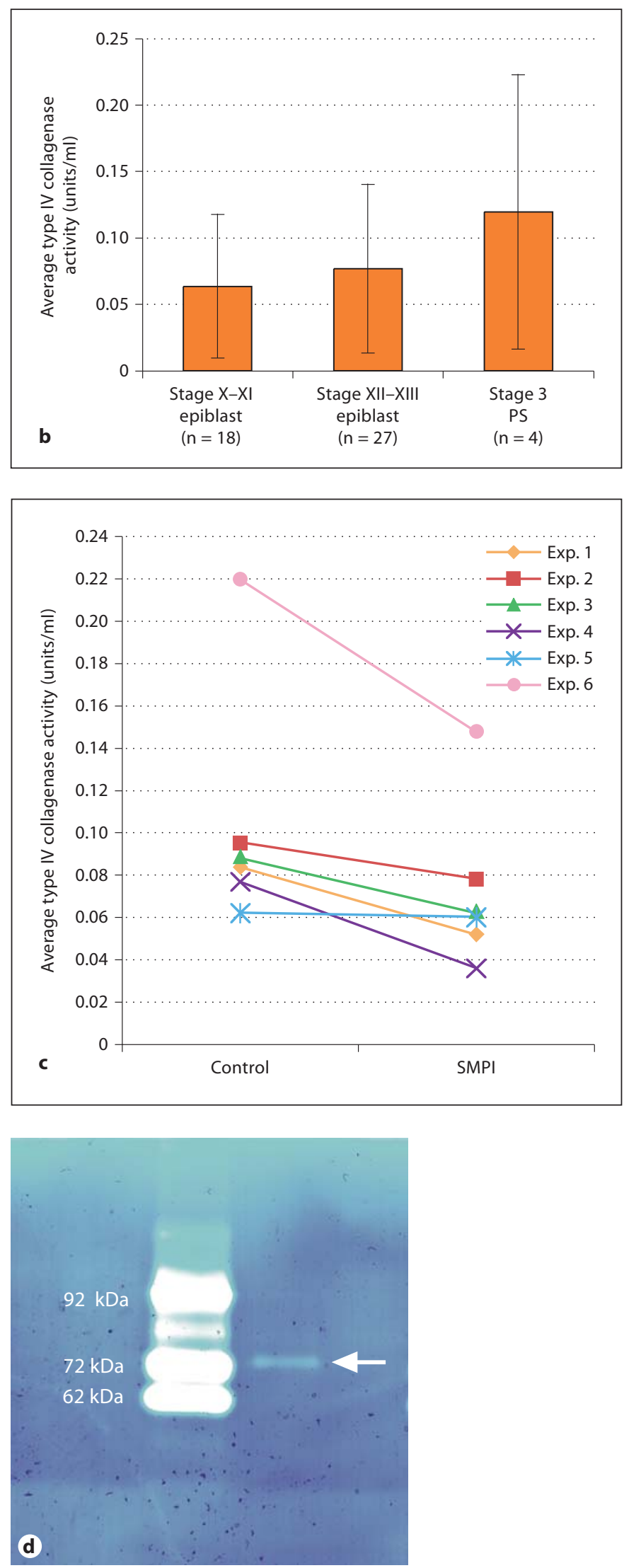
es were inverted and floated in a larger culture dish filled with the same medium. This resulted in the positioning of the gel substratum on the roof of the dish (fig. 1). The single cells also dissolved the laminin gel/EHS gel in this hanging culture, creating holes by invasive behavior in a manner very similar to that in the normal culture (fig. $2 \mathrm{~b}$, d). These results suggest that when the epiblast cells differentiate to form the mesendoderm, they firmly attach to the basement membrane components and dissolve the substratum concurrently, irrespective of the orientation with respect to gravity.

\section{Epiblast Cells Dissolve the Basement Membrane by}

Secreting Proteinase(s) That Degrade the Membrane Components

Type IV collagen is a major basement membrane component [Kleinman et al., 1982; Yurchenco and Ruben, 1987; Charonis et al., 2005]. Cancer cells dissolve the basement membrane underlying the cell by secreting MMP2/MMP-9 (gelatinases A/B) [Nakada et al., 2003; Turpeenniemi-Hujanen, 2005]. A 72-kDa pro-MMP-2 enzyme is present in the chick embryo [Stefansson et al., 1994; Alexander et al., 1997; Hahn-Dantona et al., 2000], and a chicken 75-kDa gelatinase B (MMP-9)-like enzyme has also been identified [Hahn-Dantona et al., 2000; Tong et al., 2003]. On the basis of our results from epiblast culture on a basement membrane gel, we hypothesized that the epiblast cells had dissolved the basement membrane enzymatically to invade it. To test this, we seeded epiblast cells of E-G\&K stage X-XIII embryos onto an EHS gel, cultured them for $48 \mathrm{~h}$ and observed their morphology using a scanning electron microscope. The cells made holes in the gel by dissolving the gel components and then adhered to the bottoms or walls of the holes (fig. 3a). Traces of proteolysis around the holes were visible with the scanning electron microscope.

Next, we tested the idea that the epiblast sheet secretes proteinase(s) capable of degrading basement membrane components. E-G\&K stage X-XIII epiblast cells or H\&H stage 3 primitive streak cells were excised as a sheet by microsurgery, cut into smaller pieces, transferred into uncoated 96-well polystyrene plates and cultured for $48 \mathrm{~h}$. Conditioned media were then collected and checked for MMP-2/MMP-9 (gelatinase or type IV collagenase) activity by measuring the fluorescence intensity of the degraded substrate. Enzymatic activity capable of dissolving type IV collagen was detected in media from both prestreak epiblasts and streak cells (fig. $3 \mathrm{~b}$ ). The average enzymatic activity in epiblast cells from E-G\&K stage XXIII embryos was 0.072 units $/ \mathrm{ml}(\mathrm{n}=45$; fig. $3 \mathrm{~b})$, and the

MMP Activity Is Needed for Chick

Gastrulation maximum value of enzymatic activity was 0.35 units $/ \mathrm{ml}$. The average and maximum values of enzymatic activity for $\mathrm{H} \& \mathrm{H}$ stage 3 primitive streak cells were 0.12 and 0.27 units $/ \mathrm{ml}$, respectively ( $\mathrm{n}=4$; fig. $3 \mathrm{~b}$ ).

After stage XIII epiblast cells were cultured for $48 \mathrm{~h}$, the conditioned media were divided into 2 equal volumes; 1 was used as an untreated control, and the other was supplemented with the MMP inhibitor (SMPI). MMP activity was then measured in each culture supernatant. When the MMP inhibitor SMPI was added to the conditioned medium at a dose of 7,670 or 11,500 PIU/ml just before measurement of MMP activity, enzymatic activity decreased significantly to $70 \%$ of the activity of the control medium on average $(n=6 ; p<0.025$; fig. $3 c)$. The reduction of enzymatic activity in the conditioned media by SMPI suggests that the culture supernatants from the epiblast cells contained 1 or more MMP enzymes.

\section{Detection of a 72-kDa MMP by Gelatin Zymography}

As a first step toward identifying the MMPs in epiblast cells, we used gelatin zymography to investigate the molecular weight of the MMP(s) secreted by the prestreak epiblasts/streak-stage cells. Prestreak cells were cultured in a fibronectin-coated 96-well plate, and the conditioned medium was analyzed with gelatin zymography. A weak MMP band was detected that had the same mobility as a 72-kDa marker (MMP-2 proenzyme) on electrophoresis (fig. 3d). Similarly, gelatin zymography of conditioned medium from primitive streak cells at $\mathrm{H} \& \mathrm{H}$ stage 3 showed an MMP band at the same position as a $72-\mathrm{kDa}$ marker (data not shown), indicating that the MMP in primitive streak cells is the same molecular weight as that in epiblast cells. Chicken MMP-2 is secreted as an inactive proenzyme (72-kDa pro-MMP-2) and then converted into active, mature MMP-2 $(66 \mathrm{kDa})$ by MT-MMP [Alexander et al., 1997; Su et al., 2003]. The 72-kDa MMP band detected in our zymography experiment might therefore be pro-MMP-2. These results suggest that epiblast cells secrete MMP-2 (i.e. $72-\mathrm{kDa}$ gelatinase) at the prestreak stage and then the enzyme is activated during streak formation.

\section{Epiblast Cells Are Committed to Secrete Gelatinase(s)} before Primitive Streak Formation

Cancer cell biology research has shown that membrane-binding MT-MMP activates MMP-2 [Sato and Seiki, 1996; Polette and Birembaut, 1998; Sakakibara et al., 1999; Hofmann et al., 2000a, b; Worley et al., 2003]. In later-stage chick embryos, full-length MMP-2 [Aimes et al., 1994; Cantemir et al., 2004; Linask et al., 2005], MMP- 
9 [Tong et al., 2003], 75- $k$ Da gelatinase $B$ [Tong et al., 2003], MMP-27 [Yang et al., 1998], MT3-MMP [Yang et al., 1996] and MMP-13 [Zijlstra et al., 2004] have been cloned. In this study, we used RT-PCR to investigate whether epiblast cells express $M M P-2$ and $M T 3-M M P$ mRNAs before or during primitive streak formation.

We collected and purified total RNA from epiblasts at E-G\&K stage XIII or initial streak cells at H\&H stage 3 and analyzed them for the expression of $M M P-2$ and MT3-MMP mRNAs, as well as for the expression of GAPDH mRNA as a loading control. RT-PCR products for MMP-2 and MT3-MMP were detected in the cells before and during primitive streak formation (fig. 4a). We inserted these RT-PCR products into the pGEM-T-Easy vector, sequenced them using the dye terminator method (8 clones for MMP-2, 14 clones for MT3-MMP) and confirmed them with a BLAST search to be chick MMP-2 (GenBank accession number U07775) and chick MT3$M M P$ (GenBank accession number U66463).

The expression of MMP-2 mRNA was weak in both prestreak epiblast cells and primitive streak cells, but relatively strong in the epiblast cells around the primitive streak. The expression of MT3-MMP mRNA was fairly continuous during the stages examined (fig. 4a). These results suggest that $M M P-2$ and $M T 3-M M P$ mRNAs are expressed in the epiblast cells prior to primitive streak formation and that these MMPs would be activated in the region where ingression takes place.

Next, using degenerate PCR primer sets targeting chick MMPs [Yang et al., 1996], we attempted to identify novel MMP genes expressed in the early chick blastoderm. Following RT-PCR, we detected a single DNA band of about 500 base pairs (fig. $4 \mathrm{~b}$ ). We extracted this product and ligated it into the pGEM-T-Easy vector, and each clone was then sequenced. We sequenced a total of 30 clones derived from E-G\&K stage XIII epiblast cells and 30 clones from $\mathrm{H} \& \mathrm{H}$ stage 3-3+ primitive streak cells, and 21 clones out of the 60 (35\%) were identified as the MT3-MMP gene (14 clones derived from the epiblast cells, 7 clones derived from the primitive streak cells). The putative partial amino acid sequence of these clones is presented in figure $4 \mathrm{c}$ and is slightly different from the registered sequence of the chick MT3-MMP gene; it has 3 additional bases in 2 locations compared to that of the registered chick MT3-MMP sequence, resulting in a frame shift (fig. 4c). This disparity could reflect differences in chick strains.

In addition, a novel partial sequence was identified in 14 of the 60 clones $(23 \%$; 3 clones derived from the epiblast cells, 11 clones derived from the primitive streak cells). The putative amino acid sequence of this gene (fig. 4d) showed $87 \%$ identity (by BLASTx) to Xenopus stromelysin-3 (XMMP-11; GenBank accession number AY310397). The subtilisin-like proprotein convertase [protein convertase (PC) 1, furin] cleaves an RXXR (-Arg$\mathrm{X}$-X-Arg-) motif in both pro-MMP-2 [Cao et al., 2005] and MT-MMP [Imai et al., 1996; Ota et al., 1998; Pei, 1999a, b; Matsuda et al., 2003]. The putative amino acid sequence of the newly identified chick stromelysin-3 also contains the RXXR cleavage motif (fig. 4d). We also identified another clone with homology to chick MMP-15 (MT2-MMP; GenBank accession number XM_413995; data not shown). These results suggest that various $M M P$ mRNAs are expressed and activated in the epiblast cells and primitive streak cells both before and during primitive streak formation; the inactive forms of the MMP enzymes are secreted and are then activated for primitive streak formation, dissolving the basement membrane and allowing mesendodermal cells to ingress into the blastocoele.

\section{Injection of MMP Inhibitors into the Subgerminal Cavity of the Epiblast Suppresses Primitive Streak Formation}

We next investigated whether ingression in the presumptive primitive streak region was affected by the injection of MMP inhibitors. Prior to hypoblast sheet formation, freshly laid chicken eggs possess a large space underlying the undifferentiated epiblast, which is called the subgerminal cavity. Embryos were incubated overnight with gentle shaking at $38^{\circ} \mathrm{C}$ after injecting into the subgerminal cavity of the embryos at E-G\&K stage X-XI with an MMP inhibitor mixture, GM 6001 or the negative control compound for GM 6001. Nile blue was added to the solutions to verify that the inhibitor/control compound was present under the area pellucida of the epiblast throughout the incubation (fig. 5a). In embryos injected with $50 \%$ DMSO as a control or without injection, both the primitive streak and primitive groove formed normally in almost all the embryos [injection of $50 \%$ DMSO, $94 \%$ normal ( $\mathrm{n}=48 / 51)$, fig. $5 \mathrm{~b}$, f; no injection, $98 \%$ normal $(n=39 / 40)$, fig. $5 f]$.

In contrast, in the embryos injected with the MMP inhibitor mixture or GM 6001, the formation of the primitive streak and primitive groove was greatly inhibited (fig. $5 c, d, f$ ). The MMP inhibitor mixture suppressed the formation of both the primitive streak and primitive groove in 21 of 43 injected embryos (49\%; fig. 5c, f). In some of the injected embryos, a full-length primitive streak formed as an axial cell condensation, but the prim- 

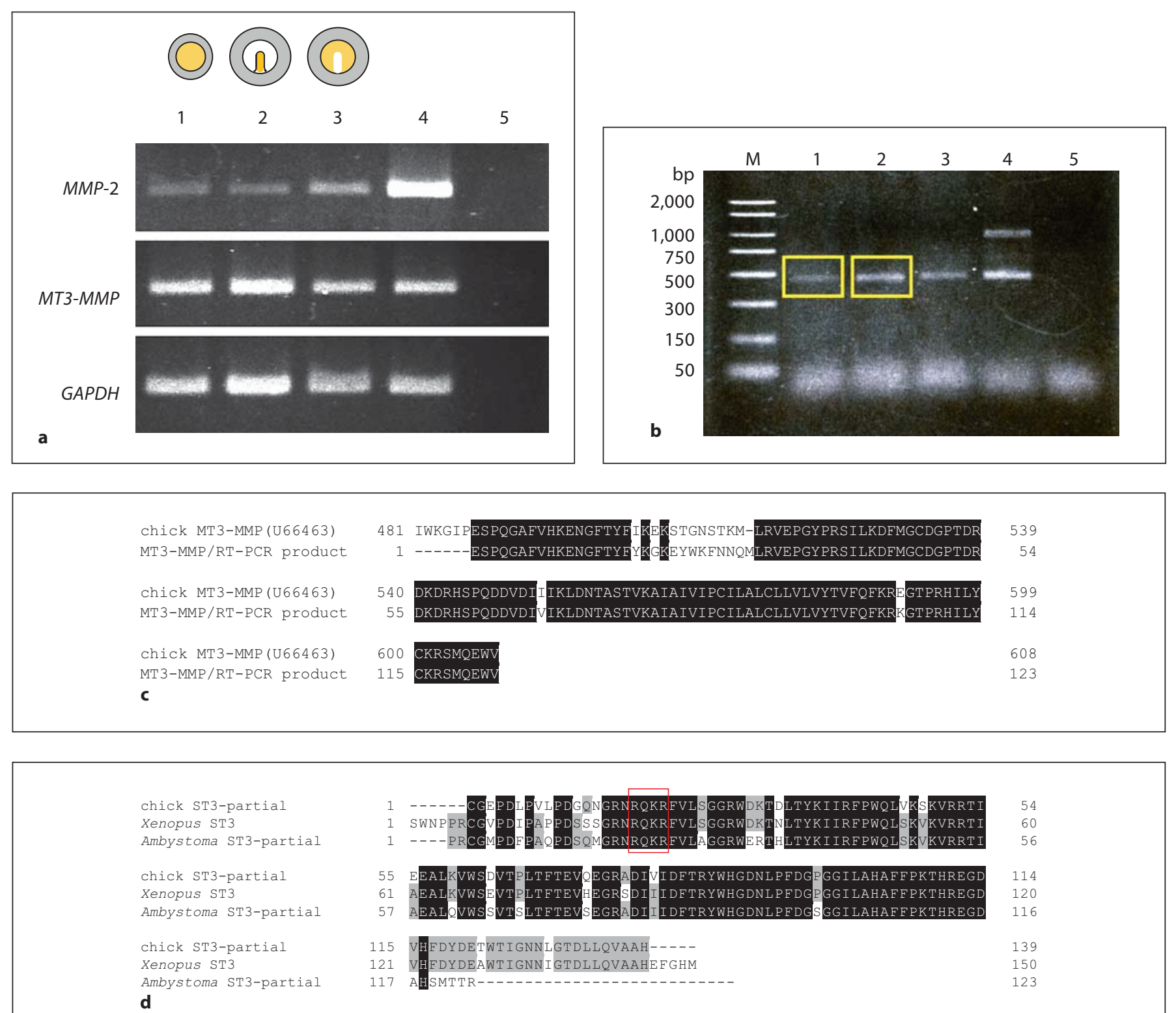

54
60
56

114
120
116
139
150
123

Fig. 4. mRNAs of $M M P-2, M T 3-M M P$ and stromelysin-3 are expressed in the epiblast cells before and during primitive streak formation. a Following dissection of epiblast sheets or primitive streak cells from embryos of E-G\&K stage XIII or H\&H stage 3-3+, the expression of the mRNAs for MMP-2, MT3-MMP and GAPDH (loading control) were examined by RT-PCR. MMP-2 and $M T 3-M M P$ products were detected in all of the samples, suggesting that the MMP-2 proenzyme is activated by MT3-MMP for the ingression of mesendodermal cells. Lane 1: stage XIII epiblast; lane 2: stage 3-3+ primitive streak; lane 3: stage 3-3+ epiblast without primitive streak; lane 4: stage 13-14 whole embryo; lane 5: -dT. b RT-PCR with degenerate primers [Yang et al., 1996] was used to search for novel MMP family members, and gene fragments of about $500 \mathrm{bp}$ were obtained from various samples. The origins of the total RNAs in lanes 1-5 were identical to those shown in a. Lane M: molecular markers. c After the PCR products shown in yellow frames in $\mathbf{b}$ were inserted into pGEM-T-Easy vectors, 60 clones were sequenced. Twenty-one clones were identified as the chick MT3-MMP gene $(35 \%, \mathrm{n}=21 / 60 ; 14$ clones derived from the epiblast cells, 7 clones derived from the primitive streak cells). The putative amino acid sequence of this gene was determined, and we found that it was slightly different to that of the registered chick MT3-MMP sequence (GenBank accession number U66463) due to a frame shift induced by 3 additional bases in 2 locations compared to the registered sequence. $\mathbf{d}$ A novel gene was identified in 14 of the 60 clones $(23 \%, \mathrm{n}=14 / 60$; 3 clones derived from epiblast cells, 11 clones derived from primitive streak cells). This gene was homologous to Xenopus stromelysin-3 (XMMP-11; GenBank accession number AY310397; 87\% identity). The putative amino acid sequence of this gene contained the RXXR cleavage motif (indicated with a red frame). 
itive groove failed to form $(33 \%, \mathrm{n}=14 / 43$; fig. $5 f)$. After the GM 6001 injection, neither the primitive streak nor the primitive groove formed in 32 of 72 embryos (44\%; fig. $5 \mathrm{~d}$ ), and a full-length primitive streak without a primitive groove was observed in 22 of 72 embryos (31\%). Some of the embryos injected with GM 6001 showed a defective primitive streak with a primitive groove $(11 \%$, $n=8 / 72$; fig. 5f). Overall, after the injection of the MMP inhibitor(s), more than $82 \%$ of the embryos showed some axial defects. Despite such axial defects, in the MMP inhibitor-injected embryos, the size of the blastodisc was normal for $\mathrm{H} \& \mathrm{H}$ stage 4 embryos, and the surface of the epiblast was smooth. On the other hand, after the injection of the negative control compound for GM 6001, both the primitive streak and the primitive groove developed normally in $71 \%$ of the injected embryos ( $n=41 / 58$; fig. 5e, f) and no embryos lacking both the primitive streak and primitive groove were observed $(n=0 / 58$; fig. 5f). This negative control experiment demonstrated that inhibition of chick gastrulation by GM 6001 was caused by the suppression of MMP activity in the chick blastoderm. These results suggest that MMP activity is required for the ingression of presumptive mesendodermal cells.

\section{Discussion}

MMPs play important roles in mammalian development [Bischof et al., 2000; Pilka et al., 2003]. In mouse embryos, when trophoblast cells are implanted in the uterine wall, mRNAs for MMP-2 and MMP-9 are expressed, and these enzymes are activated at the implantation stage. The levels of these enzymes then increase as development proceeds [Liu et al., 2006]. MMPs have also been isolated in both amphibian and sea urchin embryos, where they are expressed in the gastrulae [Robinson, 1997; Suzuki et al., 2001]. Even though several MMPs have been isolated from chicken embryos [Aimes et al., 1994; Yang et al., 1996, 1998; Lei et al., 1999; Tong et al., 2003; Cantemir et al., 2004; Zijlstra et al., 2004; Linask et al., 2005], the role of MMPs in early chick development remains obscure.

In chick embryos at the primitive streak stage, epiblast cells ingress to form the ectoderm, mesoderm and endoderm. Mesendodermal cells must pass through the basement membrane underlying the epiblast sheet; however, little is known about the mechanism by which they do this. Our results suggest that mRNAs for $M M P-2$ and MT3-MMP are expressed in the epiblast cells of the early chick embryo and that the activated MMP(s) contribute to the downward movement of the mesendodermal cells by dissolving the basement membrane.

\section{Epiblast Cells Invaginate to Form Mesendoderm by}

Enzymatically Dissolving the Basement Membrane

When epiblast cells were isolated before and during primitive streak formation and cultured on laminin gels or EHS gels containing basement membrane components, the cells made holes in the gel matrix and adhered to the pits of the holes within $24 \mathrm{~h}$ under normal culture conditions (fig. 2a, 3a). Similar invasive behavior was observed in hanging cultures, in which the downward force of gravity would have acted to detach the cells from the gel substratum (fig. $2 \mathrm{~b}, \mathrm{~d}$ ). This result suggests that the holes are formed in the gel bed by an enzymatic process and that epiblast cells on their own (without the help of the hypoblast) are capable of secreting the enzymes needed to dissolve the gel matrix while remaining attached to the gel substratum.

In mouse embryos, E-cadherin and MMPs are highly expressed during implantation [Liu et al., 2006]. Furthermore, MT5-MMP is involved in the processing of cadherins at the implantation stage [Monea et al., 2006]. In the chicken embryo, when epiblast cells were placed onto isolated blastoderm along the primitive streak in vitro, they increased the expression of $\mathrm{N}$-cadherin and inversely decreased the expression of E-cadherin, and finally they ingressed through the primitive streak [DeLuca et al., 1999]. In this study, after epiblast cells and primitive streak cells were cultured on the basement membrane gel, our scanning electron microscopy observations showed that the cells made holes by dissolving the gel matrix (fig. 3a). These results suggest that chick cadherins are possible coordinators of the MMP-dependent ingression process along the primitive streak.

We detected MMP enzymatic activity in conditioned media from both epiblast cells and primitive streak cells using fluorescently labeled type IV collagen (fig. 3b), and the activity was successfully reduced by SMPI (fig. 3c). MMP has a zinc-coordinated catalytic domain, and its activity is calcium-dependent. The main components of the basement membrane are laminin, fibronectin and type IV collagen, all of which are known substrates for MMPs [Foidart et al., 1980; Sage, 1982; Kleinman et al., 1982; Yurchenco and Ruben, 1987]. Taken together, our results from the culture supernatants suggest that epiblast cells and primitive streak cells secrete MMPs to dissolve basement membrane components, thus producing the characteristic invagination observed in our single-cell culture system. 

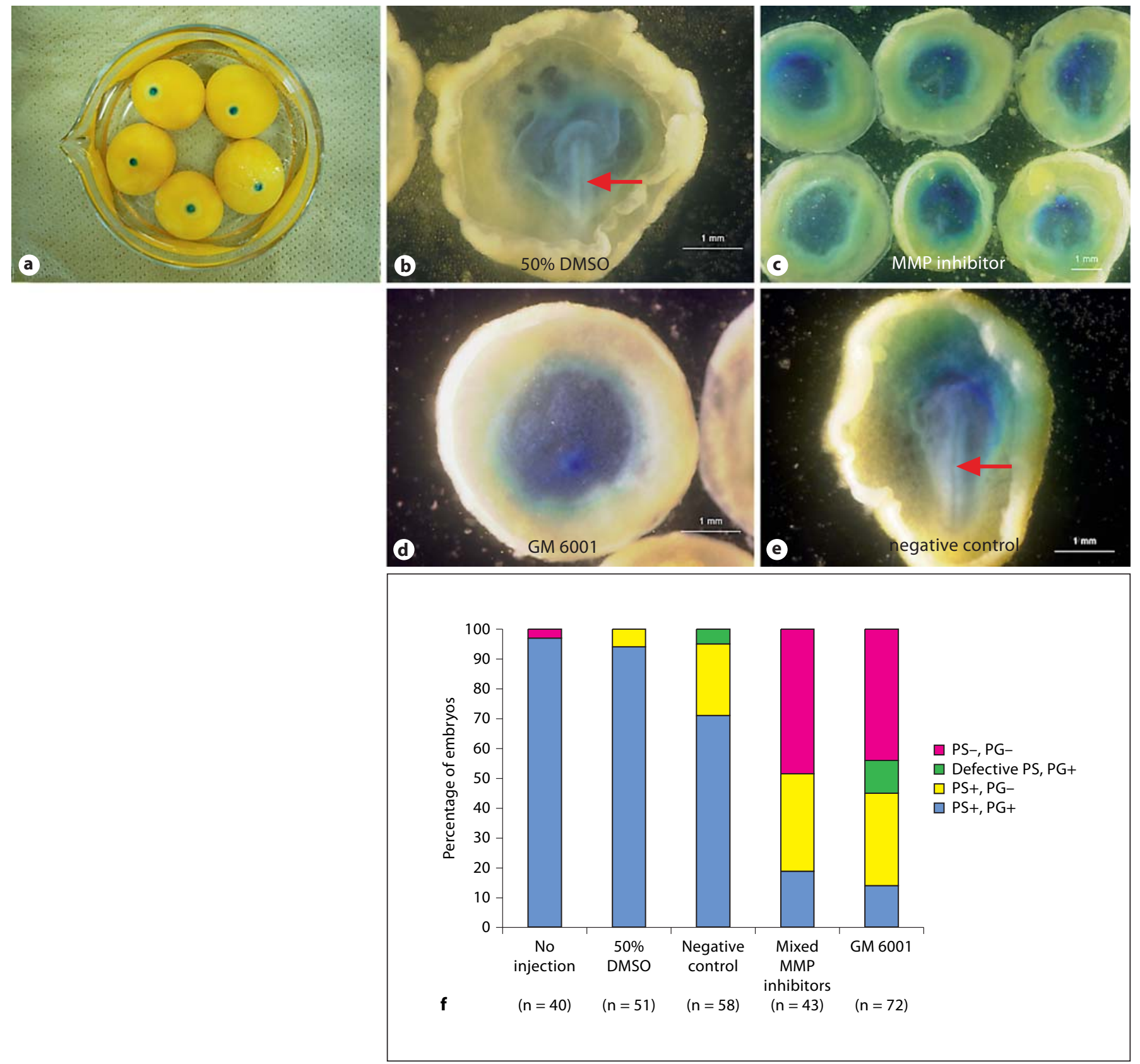

Fig. 5. In ovo injection of MMP inhibitors and resultant defects in axial structures. a Blastoderms were incubated for $24-27 \mathrm{~h}$ after injection of inhibitors into the subgerminal cavity. The Nile blue tracer indicates that the injected MMP inhibitor solutions were kept underneath the area pellucida of the epiblast. b An embryo injected with $50 \%$ DMSO. Both the primitive streak and primitive groove have formed normally. The arrow indicates the primitive groove. c Embryos injected with MMP inhibitors. Some embryos lacked primitive grooves while others failed to form both the primitive streak and primitive groove. Note that, irrespective of the state of primitive streak/primitive groove formation, the sizes of the blastodiscs were about the same for all the injected embryos. d An embryo injected with GM 6001. Note that neither the primitive streak nor the primitive groove has formed, whereas the size of the blastodisc is normal for an $\mathrm{H} \& \mathrm{H}$ stage 4 embryo and the surface of the epiblast is smooth. Scale bar $=1 \mathrm{~mm}$. e An embryo injected with a negative control compound for GM 6001. As seen with embryos injected with $50 \%$ DMSO (b), both the primitive streak and the primitive groove formed normally. f Rates of primitive streak and primitive groove formation in the embryos injected with 50\% DMSO alone, the MMP inhibitor mixture, GM 6001 or the negative control compound for GM 6001 , or with no injection. In the cases where the MMP inhibitor mixture or GM 6001 was injected, neither the primitive streak nor the primitive groove formed in $44-49 \%$ of the injected embryos. $\mathrm{PS}=$ Primitive streak; $\mathrm{PG}=$ primitive groove . 
Using gelatin zymography, we found that conditioned medium from epiblast cells or primitive streak cells contained a 72-kDa MMP enzyme (fig. 3d). Considering that gelatinase activity was present in the media conditioned by cells of the prestreak and streak stages, we deduced that MMP was secreted as a proenzyme and then activated for dissolving basement membrane during the invagination process at the streak stage.

To date, the following full-length genes have been cloned from the developing chick embryo: MMP-2 [Aimes et al., 1994; Cantemir et al., 2004; Linask et al., 2005], MMP-9 [Tong et al., 2003], 75- $k$ Da gelatinase B [HahnDantona et al., 2000; Tong et al., 2003], MMP-27 [Yang et al., 1998], MT3-MMP [Yang et al., 1996] and MMP-13 [Zijlstra et al., 2004]. MMP-2 is also known as gelatinase A, $72-\mathrm{kDa}$ type IV collagenase and $72-\mathrm{kDa}$ gelatinase. The $72-\mathrm{kDa}$ pro-MMP-2 is processed to a $62-\mathrm{kDa}$ active MMP-2 form in humans [Olson et al., 1997] and calves [Lakritz et al., 2004]. In contrast, the $72-\mathrm{kDa}$ chicken proMMP-2 is converted into a $66-\mathrm{kDa}$ active MMP-2 [Alexander et al., 1997; Su et al., 2003].

MMP-9 is also known as gelatinase B, 92-kDa type IV collagenase and $92-\mathrm{kDa}$ gelatinase. The $92-\mathrm{kDa}$ proMMP-9 is processed to an 82-kDa active MMP-9 form in humans [Olson et al., 1997] and calves [Lakritz et al., 2004]. A chicken-specific 75-kDa MMP-9-like enzyme has been identified [Hahn-Dantona et al., 2000; Tong et al., 2003]. This enzyme is reported to be processed into $60-, 55-$ or $50-\mathrm{kDa}$ products from the $75-\mathrm{kDa}$ inactive form [Hahn-Dantona et al., 2000]. In light of this, we presume that the $72-\mathrm{kDa}$ MMP detected in our zymography is chick pro-MMP-2.

We obtained only a single band in gelatin zymography, perhaps because only a small volume of MMP-2 is activated locally, preventing detection of the active form. Although we identified $3 M M P$ s, i.e. $M M P-2, M T 3-M M P$ and $M M P-11$, by RT-PCR analyses of mRNA profiles derived from epiblast cells or primitive streak cells (fig. 4), only MMP-2 protein was detected by gelatin zymography of these tissues (fig. 3d). The discrepancy between the RT-PCR analyses and gelatin zymography could be partly due to anchorage of the MT-MMP to the plasma membrane; because MT3-MMP has a transmembrane domain, the secreted pro-MT3-MMP might be quickly anchored to the cytomembrane, and MT3-MMP might not be discharged into the conditioned medium. However, differences in the sensitivity of the methods could also have contributed to these results.
Expression of MMP-2 and MT3-MMP in Epiblast

Cells before Ingression and Their Possible Functions

Our results show that epiblast cells and primitive streak cells have the potential to degrade type IV collagen and other basement membrane components before and during ingression (fig. 2, 3). Proteolysis of fluorescently labeled type IV collagen using conditioned media indicated that epiblast cells secrete MMP(s) with gelatinase activity. We detected PCR products of MMP-2 and MT3$M M P$ in various prestreak/streak cells (fig. $4 \mathrm{a}$ ). In mammals, MMP-2 is activated by MT-MMPs and cannot be activated by autocatalysis [Sato and Seiki, 1996; Sakakibara et al., 1999; Nie and Pei, 2003]. Early investigations suggested that MT-MMP is involved in the activation of MMP-2 in chick cardiac cells [Alexander et al., 1997]. Because we identified MT3-MMP in prestreak/streak cells in this study, it is possible that MMP-2, which is secreted from these cells in its inactive form, may be activated by MT3-MMP during chick gastrulation.

Recently, in human macrophages, PC1 (furin) and PC5 were found to be involved in the activation of MT1MMP. MT1-MMP, together with PC1 and PC5, then converts pro-MMP-2 to the active form in macrophages [Stawowy et al., 2005]. MT-MMP is the membrane-bound form of MMP and has a cleavage site in its RXXR motif [Imai et al., 1996; Ota et al., 1998; Pei, 1999a, b; Matsuda et al., 2003]. Pro-MMP-2 [Cao et al., 2005] and pro-MT1MMP [Remacle et al., 2006] are known in particular to be cleaved by furin, and human stromelysin-3 is also activated by furin-dependent cleavage [Pei and Weiss, 1995]. Administration of the PC inhibitor decanoyl-RVKRchloromethyl ketone to human macrophages inhibits the activity of MT1-MMP [Stawowy et al., 2005], and thus it is thought that PCs have an important role in activating MT1-MMP. Although PC1 (furin), PC4 (PACE4), PC6 and $\mathrm{PC}$, which belong to the subtilisin-like proprotein convertase family, have been cloned using a cDNA library derived from chicken liver [Feldmann et al., 2000], little has been reported about the expression patterns of these PCs and their processing cascades in the chick embryo. The mechanism of MMP/MT-MMP activation by these processing enzymes in early chick blastoderm will be an interesting topic for future investigations.

In this study, we cloned a partial sequence for chick stromelysin-3 by RT-PCR using degenerate primers and showed that it is highly homologous ( $87 \%$ identity by BLASTx search) to Xenopus MMP-11 (Xenopus stromelysin-3) [Patterton et al., 1995; Ishizuya-Oka et al., 1996, 2000]. The cleavage site (RXXR motif) of the chick stromelysin-3 gene was identified in the partial sequence by 
BLASTx analysis (fig. 4d). XMMP-11 is involved in apoptosis at the tail region during metamorphosis of Xenopus [Damjanovski et al., 1999], and, interestingly, it is expressed in the future posterior end at the mid-neurula stage [Damjanovski et al., 2000]. It is possible that chick stromelysin-3 plays an important role in the ingression movement during chick primitive streak formation, which is initiated at the posterior portion of the area pellucida. Our next step will be to clone the full-length chick stromelysin-3 and to analyze its expression pattern and activation mechanism, which may have been lost in our cell culture system.

In ovo Injection Experiment Shows that MMPs

Are Involved in Primitive Streak/Primitive Groove

Formation in the Chick Embryo

We demonstrated that in the early chick embryo, epiblast cells at the prestreak stage express mRNAs of 3 MMPs, i.e. $M M P-2, M T 3-M M P$ and $M M P-11$, and secrete a 72-kDa gelatinase (probably pro-MMP-2; fig. 3, 4). Injection of GM 6001 or a mixture of other MMP inhibitors into the subgerminal cavity of the embryo suppressed the formation of both the primitive streak and primitive groove in $44-49 \%$ of the embryos (fig. $5 c, d, f$ ). GM 6001 is a potent inhibitor of various MMPs in tumor invasion [Boghaert et al., 1994; Santibáñez et al., 2002; Yeh et al., 2006] and has been reported to inhibit fin regeneration in zebrafish [Bai et al., 2005]. The present study reveals that at least 3 kinds of MMPs continue to be localized in the area pellucida from the prestreak stage to the streak stage (fig. 3, 4), and, furthermore, injection of either GM 6001 or a mixture of other MMP inhibitors completely inhibits the formation of both the primitive streak and primitive groove in up to $50 \%$ of the injected embryos (fig. 5). These results strongly suggest that MMPs have an important role in ingression in the early chick embryo. Injection of an MMP-2 inhibitor alone did not suppress the formation of the primitive streak/primitive groove (data not shown), which may reflect the involvement of an unidentified MMP other than MMP-2 in the ingression movement.

In human tumors, pro-MMP-2 forms a molecular complex with MT1-MMP and tissue inhibitor of matrix metalloproteinase (TIMP)-2, and formation of this complex at the periphery of the plasma membrane is needed for the conversion of the MMP-2 enzyme from the inactive to the active form [Teti et al., 1998]. Chick TIMP-1 [Ozyigit et al., 2005; Huh et al., 2007], chick TIMP-2 [Aimes et al., 1998; Cantemir et al., 2004] and chick TIMP3 [Yang and Hawkes, 1992] have been cloned; of these,
TIMP-2 is known to be involved in pro-MMP-2 activation [Cantemir et al., 2004]. Similarly, MT3-MMP is also known to activate pro-MMP-2 at the cell surface to mature MMP-2 in human tumors and rheumatoid synovia [Kitagawa et al., 1998; Nakada et al., 1999; Yamanaka et al., 2000]. On the basis of the results of our in ovo injection experiments, we suggest that primitive streak/primitive groove formation in the chick blastoderm requires the enzymatic action of both MMP-2 and MT3-MMP as an activator of pro-MMP-2; in other words, both MMPs may be essential for axis formation in the chick blastoderm.

\section{Concluding Remarks}

From the results of the present study, we conclude that ingression of the epiblast requires MMP activity during gastrulation of the chick embryo. Epiblast cells secrete MMPs and migrate toward the blastocoelic cavity by dissolving the basement membrane during primitive streak formation, and MMPs appear to be essential for the ingression of mesendodermal cells during chick gastrulation. This study strongly suggests that ingression is essentially similar to the process of invasion by cancer cells. Interactions between MT3-MMP, pro-MMP-2 and possibly protein convertase(s) that could lead to the activation of MMP-2 will be a fascinating area of investigation for the future.

\section{Acknowledgements}

We deeply thank Emeritus Professor Shigeo Takeuchi for encouraging our work. We also thank Kimiyo Mitsumura (hanging culture), Kuniko Hayatsu (measurement of gelatinase activity) and Mitsuyo Tsuma (part of the RT-PCR analysis) for technical assistance.

\footnotetext{
References Ahokas, K., J. Lohi, H. Lohi, O. Elomaa, M.L. Karjalainen-Lindsberg, J. Kere, U. Saarialho-Kere (2002) Matrix metalloproteinase21, the human orthologue for XMMP, is expressed during fetal development and in cancer. Gene 301: 31-41

Aimes, R.T., D.L. French, J.P. Quigley (1994) Cloning of a $72 \mathrm{kDa}$ matrix metalloproteinase (gelatinase) from chicken embryo fibroblasts using gene family PCR: expression of the gelatinase increases upon malignant transformation. Biochem J 300: 729-736.
} 
Aimes, R.T., L.H. Li, B. Weaver, S. Hawkes, E.A. Hahn-Dantona, J.P. Quigley (1998) Cloning, expression, and characterization of chicken tissue inhibitor of metalloproteinase-2 (TIMP-2) in normal and transformed chicken embryo fibroblasts. J Cell Physiol 17: 342352.

-Alexander, S.M., K.J. Jackson, K.M. Bushnell, P.G. McGuire (1997) Spatial and temporal expression of the 72-kDa type IV collagenase (MMP-2) correlates with development and differentiation of valves in the embryonic avian heart. Dev Dyn 209: 261-268.

Bai, S., R. Thummel, A.R. Godwin, H. Nagase, Y. Itoh, L. Li, R. Evans, J. McDermott, M. Seiki, M.P. Sarras Jr. (2005) Matrix metalloproteinase expression and function during fin regeneration in zebrafish: analysis of MT1MMP, MMP2 and TIMP2. Matrix Biol 24: 247-260.

Bellairs, R., M.C. van Peteghem (1984) Gastrulation: is it analogous to malignant invasion. Am Zool 24: 563-570.

-Bischof, P., A. Meisser, A. Campana (2000) Mechanisms of endometrial control of trophoblast invasion. J Reprod Fertil 55: 65-71.

Boghaert, E.R., S.K. Chan, C. Zimmer, D. Grobelny, R.E. Galardy, T.C. Vanaman, S.G. Zimmer (1994) Inhibition of collagenolytic activity relates to quantitative reduction of invasion in vitro in a c-Ha-ras transfected glial cell line. J Neurooncol 21: 141-150.

Cai, D.H, P.R. Brauer (2002) Synthetic matrix metalloproteinase inhibitor decreases early cardiac neural crest migration in chicken embryos. Dev Dyn 224: 441-449.

Cai, D.H., T.M. Vollberg Sr., E. Hahn-Dantona, J.P. Quigley, P.R. Brauer (2000) MMP-2 expression during early avian cardiac and neural crest morphogenesis. Anat Rec 259: 168 179.

Cantemir, V., D.H. Cai, M.V. Reedy, P.R. Brauer (2004) Tissue inhibitor of metalloproteinase-2 (TIMP-2) expression during cardiac neural crest cell migration and its role in proMMP-2 activation. Dev Dyn 231: 709719.

Cao, J., A. Rehemtulla, M. Pavlaki, P. Kozarekar, C. Chiarelli (2005) Furin directly cleaves proMMP-2 in the trans-Golgi network resulting in a nonfunctioning proteinase. J Biol Chem 280: 10974-10980.

-Carinato, M.E., B.E. Walter, J.J. Henry (2000) Xenopus laevis gelatinase B (Xmmp-9): development, regeneration, and wound healing. Dev Dyn 217: 377-387.

-Charonis, A., V. Sideraki, V. Kaltezioti, A. Alberti, D. Vlahakos, K. Wu, E. Tsilibary (2005) Basement membrane peptides: functional considerations and biomedical applications in autoimmunity. Curr Med Chem 12: $1495-$ 1502 .
Chen, J.M., R.T. Aimes, G.R. Ward, G.L. Youngleib, J.P. Quigley (1991) Isolation and characterization of a 70-kDa metalloprotease (gelatinase) that is elevated in Rous sarcoma virus-transformed chicken embryo fibroblasts. J Biol Chem 266: 5113-5121.

Damjanovski, S., A. Ishizuya-Oka, Y.B. Shi (1999) Spatial and temporal regulation of collagenases-3, -4, and stromelysin-3 implicates distinct functions in apoptosis and tissue remodeling during frog metamorphosis. Cell Res 9: 91-105.

-Damjanovski, S., M. Puzianowska-Kuznicka, A. Ishuzuya-Oka, Y.B. Shi (2000) Differential regulation of three thyroid hormone-responsive matrix metalloproteinase genes implicates distinct functions during frog embryogenesis. FASEB J 14: 503-510.

DeLuca, S.M., J. Gerhart, E. Cochran, E. Simak, J. Blitz, M. Mattiacci-Paessler, K. Knudsen, M. George-Weinstein (1999) Hepatocyte growth factor/scatter factor promotes a switch from $\mathrm{E}$ - to $\mathrm{N}$-cadherin in chick embryo epiblast cells. Exp Cell Res 251: 3-15.

Duband, J.L., J.P. Thiery (1982) Appearance and distribution of fibronectin during chick embryo gastrulation and neurulation. Dev Biol 94: 337-350.

Eyal-Giladi, H., S. Kochav (1976) From cleavage to primitive streak formation: a complementary normal table and a new look at the first stages of the development of the chick. Dev Biol 49: 321-337.

Feldmann, A., M.K. Schafer, W. Garten, H.D. Klenk (2000) Targeted infection of endothelial cells by avian influenza virus A/FPV/ Rostock/34 (H7N1) in chicken embryos. J Virol 74: 8018-8027.

Foidart, J.M., E.W. Bere, Jr., M. Yaar, S.I. Rennard, M. Gullino, G.R. Martin, S.I. Katz (1980) Distribution and immunoelectron microscopic localization of laminin, a noncollagenous basement membrane glycoprotein. Lab Invest 42: 336-342.

Hahn-Dantona, E.A., R.T. Aimes, J.P. Quigley (2000) The isolation, characterization, and molecular cloning of a $75-\mathrm{kDa}$ gelatinase Blike enzyme, a member of the matrix metalloproteinase (MMP) family. An avian enzyme that is MMP-9-like in its cell expression pattern but diverges from mammalian gelatinase B in sequence and biochemical properties. J Biol Chem 275: 40827-40838.

Hamburger, V., H.L. Hamilton (1951) A series of normal stages in development of the chick embryo. J Morphol 88: 49-92.

-Harrison, M., M. Abu-Elmagd, T. Grocott, C. Yates, J. Gavrilovic, G.N. Wheeler (2004) Matrix metalloproteinase genes in Xenopus development. Dev Dyn 231: 214-220.

Hasebe, T., R. Hartman, H. Matsuda, Y.B. Shi (2006) Spatial and temporal expression profiles suggest the involvement of gelatinase A and membrane type 1 matrix metalloproteinase in amphibian metamorphosis. Cell Tissue Res 324: 105-116.
Hofmann, U.B., R. Houben, E.B. Brocker, J.C. Becker (2005) Role of matrix metalloproteinases in melanoma cell invasion. Biochimie 87: 307-314.

Hofmann, U.B., J.R. Westphal, A.A. van Kraats, D.J. Ruiter, G.N. van Muijen (2000a) Expression of integrin alpha(v)beta(3) correlates with activation of membrane-type matrix metalloproteinase-1 (MT1-MMP) and matrix metalloproteinase-2 (MMP-2) in human melanoma cells in vitro and in vivo. Int J Cancer 87:12-19.

Hofmann, U.B., J.R. Westphal, A.J. Zendman, J.C. Becker, D.J. Ruiter, G.N. van Muijen (2000b) Expression and activation of matrix metalloproteinase-2 (MMP-2) and its co-localization with membrane-type 1 matrix metalloproteinase (MT1-MMP) correlate with melanoma progression. J Pathol 191: 245-256.

Huh, M.I., Y.M. Lee, S.K. Seo, B.S. Kang, Y. Chang, Y.S. Lee, M.E. Fini, S.S. Kang, J.C. Jung (2007) Roles of MMP/TIMP in regulating matrix swelling and cell migration during chick corneal development. J Cell Biochem 101: 1222-1237.

Imai, K., E. Ohuchi, T. Aoki, H. Nomura, Y. Fujii, H. Sato, M. Seiki, Y. Okada (1996) Membrane-type matrix metalloproteinase 1 is a gelatinolytic enzyme and is secreted in a complex with tissue inhibitor of metalloproteinases 2. Cancer Res 56: 2707-2710.

-Ishizuya-Oka, A., Q. Li, T. Amano, S. Damjanovski, S. Ueda, Y.B. Shi (2000) Requirement for matrix metalloproteinase stromelysin-3 in cell migration and apoptosis during tissue remodeling in Xenopus laevis. J Cell Biol 150: 1177-1188.

Ishizuya-Oka, A., S. Ueda, Y.B. Shi (1996) Transient expression of stromelysin-3 mRNA in the amphibian small intestine during metamorphosis. Cell Tissue Res 283: 325-329.

Jung, J.C., K.J. Leco, D.R. Edwards, M.E. Fini (2002) Matrix metalloproteinases mediate the dismantling of mesenchymal structures in the tadpole tail during thyroid hormoneinduced tail resorption. Dev Dyn 223: 402413.

Kitagawa, Y., K. Kunimi, H. Ito, H. Sato, T. Uchibayashi, Y. Okada, M. Seiki, M. Namiki (1998) Expression and tissue localization of membrane-types 1,2 , and 3 matrix metalloproteinases in human urothelial carcinomas. J Urol 160: 1540-1545.

Kleinman, H.K., M.L. McGarvey, L.A. Liotta, P.G. Robey, K. Tryggvason, G.R. Martin (1982) Isolation and characterization of type IV procollagen, laminin and heparan sulfate proteoglycan from the EHS sarcoma. Biochemistry 21: 6188-6193.

Lakritz, J., A.E. Marsh, M. Cockrell, M.F. Smith, J.W. Tyler (2004) Characterization of gelatinases in bronchoalveolar lavage fluid and gelatinases produced by alveolar macrophages isolated from healthy calves. Am J Vet Res 65: 163-172. 
Lei, H., E.E. Furth, R. Kalluri, P. Wakenell, C.B. Kallen, J.J. Jeffrey, P.S. Leboy, J.F. Strauss 3rd (1999) Induction of matrix metalloproteinases and collagenolysis in chick embryonic membranes before hatching. Biol Reprod 60: 183-189.

Linask, K.K., M. Han, D.H. Cai, P.R. Brauer, S. M. Maisastry (2005) Cardiac morphogenesis: matrix metalloproteinase coordination of cellular mechanisms underlying heart tube formation and directionality of looping. Dev Dyn 233: 739-753.

Liu, G., X. Zhang, H. Lin, H. Wang, Q. Li, J. Ni, C. Zhu (2006) Effects of E-cadherin on mouse embryo implantation and expression of matrix metalloproteinase- 2 and -9. Biochem Biophys Res Commun 343: 832-838.

Matsuda, A., Y. Itoh, N. Koshikawa, T. Akizawa, I. Yana, M. Seiki (2003) Clusterin, an abundant serum factor, is a possible negative regulator of MT6-MMP/MMP-25 produced by neutrophils. J Biol Chem 278: 36350-36357.

Mogi, K., R. Toyoizumi, S. Takeuchi (2000) Correlation between the expression of the HNK1 epitope and cellular invasiveness in prestreak epiblast cells of chick embryos. Int J Dev Biol 44: 811-814.

Monea, S., B.A. Jordan, S. Srivastava, S. DeSouza, E.B. Ziff (2006) Membrane localization of membrane type 5 matrix metalloproteinase by AMPA receptor binding protein and cleavage of cadherins. J Neurosci 26: 23002312.

Nakada, M., H. Nakamura, E. Ikeda, N. Fujimoto, J. Yamashita, H. Sato, M. Seiki, Y. Okada (1999) Expression and tissue localization of membrane-type 1,2, and 3 matrix metalloproteinases in human astrocytic tumors. Am J Pathol 154: 417-428.

- Nakada, M., Y. Okada, J. Yamashita (2003) The role of matrix metalloproteinases in glioma invasion. Front Biosci 8: 261-269.

Nie, J., D. Pei (2003) Direct activation of pro-matrix metalloproteinase-2 by leukolysin/ membrane-type 6 matrix metalloproteinase/matrix metalloproteinase 25 at the asn(109)-Tyr bond. Cancer Res 63: 67586762.

Olson, M.W., D.C. Gervasi, S. Mobashery, R. Fridman (1997) Kinetic analysis of the binding of human matrix metalloproteinase-2 and -9 to tissue inhibitor of metalloproteinase (TIMP)-1 and TIMP-2. J Biol Chem 272: 29975-29983.

-Ota, K., W.G. Stetler-Stevenson, Q. Yang, A. Kumar, J. Wada, N. Kashihara, E.I. Wallner, Y.S. Kanwar (1998) Cloning of murine membrane-type-1-matrix metalloproteinase (MT-1-MMP) and its metanephric developmental regulation with respect to MMP-2 and its inhibitor. Kidney Int 54: 131-142.

Ozyigit, M.O., M.M. Kahraman, G. Sonmez (2005) The identification of matrix metalloproteinases and their tissue inhibitors in broiler chickens by immunohistochemistry. Avian Pathol 34: 509-516.
Patterton, D., W.P. Hayes, Y.B. Shi (1995) Transcriptional activation of the matrix metalloproteinase gene stromelysin-3 coincides with thyroid hormone-induced cell death during frog metamorphosis. Dev Biol 167: 252-262.

- Pei, D. (1999a) Identification and characterization of the fifth membrane-type matrix metalloproteinase MT5-MMP. J Biol Chem 274: 8925-8932.

Pei, D. (1999b) Leukolysin/MMP25/MT6-MMP: a novel matrix metalloproteinase specifically expressed in the leukocyte lineage. Cell Res 9: 291-303.

Pei, D., S.J. Weiss (1995) Furin-dependent intracellular activation of the human stromelysin-3 zymogen. Nature 375: 244-247.

Pilka, R., M. Kudela, M. Prochazka (2003) Matrix metalloproteinases, embryo implantation and tumor invasion (in Czech). Ceska Gynekol 68: 179-185.

- Polette, M., P. Birembaut (1998) Membrane-type metalloproteinases in tumor invasion. Int J Biochem Cell Biol 30: 1195-1202.

Remacle, A.G., D.V. Rozanov, M. Fugere, R. Day, A.Y. Strongin (2006) Furin regulates the intracellular activation and the uptake rate of cell surface-associated MT1-MMP. Oncogene 25: 5648-5655.

Robinson, J.J. (1997) Characterization of a metalloproteinase: a late stage specific gelatinase activity in the sea urchin embryo. J Cell Biochem 66: 337-345.

-Sage, H. (1982) Collagens of basement membranes. J Invest Dermatol 79: 51-59.

-Sakakibara, M., S. Koizumi, Y. Saikawa, H. Wada, T. Ichihara, H. Sato, S. Horita, H. Mugishima, Y. Kaneko, K. Koike (1999) Membrane-type matrix metalloproteinase-1 expression and activation of gelatinase $\mathrm{A}$ as prognostic markers in advanced pediatric neuroblastoma. Cancer 85: 231-239.

-Santibáñez, J.F., J. Guerrero, M. Quintanilla, A. Fabra, J. Martínez (2002) Transforming growth factor-betal modulates matrix metalloproteinase-9 production through the Ras/MAPK signaling pathway in transformed keratinocytes. Biochem Biophys Res Commun 296: 267-273.

Sato, H., M. Seiki (1996) Membrane-type matrix metalloproteinases (MT-MMPs) in tumor metastasis. J Biochem 119: 209-215.

-Soulintzi, N., N. Zagris (2007) Spatial and temporal expression of perlecan in the early chick embryo. Cells Tissues Organs 186: 243-256.

Stawowy, P., H. Meyborg, D. Stibenz, N. Borges Pereira Stawowy, M. Roser, U. Thanabalasingam, J.P. Veinot, M. Chretien, N.G. Seidah, E. Fleck, K. Graf (2005) Furin-like proprotein convertases are central regulators of the membrane type matrix metalloproteinase-pro-matrix metalloproteinase-2 proteolytic cascade in atherosclerosis. Circulation 111: $2820-2827$.
Stefansson, S., R.T. Aimes, N.B. Seward, D.S. Alexander, J.P. Quigley (1994) Native TIMPfree $70 \mathrm{kDa}$ progelatinase (MMP-2) secreted at elevated levels by RSV transformed fibroblasts. J Cell Physiol 161: 419-428.

-Stern, C.D., D.R. Canning (1990) Origin of cells giving rise to mesoderm and endoderm in chick embryo. Nature 343: 273-275.

Stolow, M.A., D.D. Bauzon, J. Li, T. Sedgwick, V.C. Liang, Q.A. Sang, Y.B. Shi (1996) Identification and characterization of a novel collagenase in Xenopus laevis: possible roles during frog development. Mol Biol Cell 7: 1471-1483.

Su, J.M., Y.Q. Wei, L. Tian, X. Zhao, L. Yang, Q.M. He, Y. Wang, Y. Lu, Y. Wu, F. Liu, J.Y. Liu, J.L. Yang, Y.Y. Lou, B. Hu, T. Niu, Y.J. Wen, F. Xiao, H.X. Deng, J. Li, B. Kan (2003) Active immunogene therapy of cancer with vaccine on the basis of chicken homologous matrix metalloproteinase-2. Cancer Res 63: 600-607.

Suzuki, A.S., Y. Tadano, T. Yamamoto, S.I. Abe, T. Tajima (2001) Expression of a novel matrix metalloproteinase gene during Cynops early embryogenesis. Biochem Biophys Res Commun 288: 380-384.

Teti, A., A.R. Farina, I. Villanova, A. Tiberio, A. Tacconelli, G. Sciortino, A.F. Chambers, A. Gulino, A.R. Mackay (1998) Activation of MMP-2 by human GCT23 giant cell tumour cells induced by osteopontin, bone sialoprotein and GRGDSP peptides is RGD and cell shape change dependent. Int J Cancer 77: 8293.

Tomlinson, M.L., C. Garcia-Morales, M. AbuElmagd, G.N. Wheeler (2008) Three matrix metalloproteinases are required in vivo for macrophage migration during embryonic development. Mech Dev 125: 1059-1070.

Tong, A., A. Reich, O. Genin, M. Pines, E. Monsonego-Ornan (2003) Expression of chicken 75 -kDa gelatinase B-like enzyme in perivascular chondrocytes suggests its role in vascularization of the growth plate. J Bone Miner Res 18: 1443-1452.

Toyoizumi, R., K. Mogi, S. Takeuchi (1997) Individual epiblast cells acquired invasiveness precedent to the primitive streak formation in the chick embryo. Zool Sci 14: 313-320.

Toyoizumi, R., S. Takeuchi (1995) The behavior of chick gastrula mesodermal cells under the unidirectional tractive force parallel to the substrata. J Cell Sci 108: 557-567.

Turpeenniemi-Hujanen, T. (2005) Gelatinases (MMP-2 and -9) and their natural inhibitors as prognostic indicators in solid cancers. Biochimie 87: 287-297.

Vihinen, P., R. Ala-aho, V.M. Kahari (2005) Matrix metalloproteinases as therapeutic targets in cancer. Curr Cancer Drug Targets 5: 203-220. 
Werner, S.R., A.L. Mescher, A.W. Neff, M.W. King, S. Chaturvedi, K.L. Duffin, M.W. Harty, R.C. Smith (2007) Neural MMP-28 expression precedes myelination during development and peripheral nerve repair. Dev Dyn 236: 2852-2864.

Worley, J.R., P.B. Thompkins, M.H. Lee, M. Hutton, P. Soloway, D.R. Edwards, G. Murphy, V. Knauper (2003) Sequence motifs of tissue inhibitor of metalloproteinases 2 (TIMP-2) determining progelatinase A (proMMP-2) binding and activation by membrane-type metalloproteinase 1 (MT1-MMP). Biochem J 372: 799-809.

-Yamanaka, H., K. Makino, M. Takizawa, H. Nakamura, N. Fujimoto, H. Moriya, R. Nemori, H. Sato, M. Seiki, Y. Okada (2000) Expression and tissue localization of membranetypes 1,2, and 3 matrix metalloproteinases in rheumatoid synovium. Lab Invest 80: 677-687.
Yang, M., K. Hayashi, M. Hayashi, J.T. Fujii, M. Kurkinen (1996) Cloning and developmental expression of a membrane-type matrix metalloproteinase from chicken. J Biol Chem 271: 25548-25554.

- Yang, M., M. Kurkinen (1998) Cloning and characterization of a novel matrix metalloproteinase (MMP), CMMP, from chicken embryo fibroblasts. CMMP, Xenopus XMMP, and human MMP19 have a conserved unique cysteine in the catalytic domain. J Biol Chem 273: 17893-17900.

Yang, M., M.T. Murray, M. Kurkinen (1997) A novel matrix metalloproteinase gene (XMMP) encoding vitronectin-like motifs is transiently expressed in Xenopus laevis early embryo development. J Biol Chem 272: 13527-13533.

Yang, T.T., S.P. Hawkes (1992) Role of the 21-kDa protein TIMP-3 in oncogenic transformation of cultured chicken embryo fibroblasts. Proc Natl Acad Sci USA 89: 10676-10680.
Yeh, M.W., J.P. Rougier, J.W. Park, Q.Y. Duh, M. Wong, Z. Werb, O.H. Clark (2006) Differentiated thyroid cancer cell invasion is regulated through epidermal growth factor receptor-dependent activation of matrix metalloproteinase (MMP)-2/gelatinase A. Endocr Relat Cancer 13: 1173-1183.

Yurchenco, P.D., G.C. Ruben (1987) Basement membrane structure in situ: evidence for lateral associations in the type IV collagen network. J Cell Biol 105: 2559-2568.

Zagris, N., A.E. Chung, V. Stavridis (2000) Differential expression of laminin genes in early chick embryo. Int J Dev Biol 44: 815-818.

Zijlstra, A., R.T. Aimes, D. Zhu, K. Regazzoni, T. Kupriyanova, M. Seandel, E.I. Deryugina, J.P. Quigley (2004) Collagenolysis-dependent angiogenesis mediated by matrix metalloproteinase-13 (collagenase-3). J Biol Chem 279: 27633-27645. 